\title{
Depressive symptoms as an independent risk factor for mortality
}

\author{
Vanessa P. Corrêa, ${ }^{1}$ iD Susana C. Confortin, ${ }^{2}$ iD Eleonora d'Orsi, ${ }^{3}$ iD Antônio R. de Sá-Junior, ${ }^{4}$ iD \\ Cesar de Oliveira, ${ }^{5}$ iD lone J.C. Schneider ${ }^{1,3}$ iD \\ ${ }^{1}$ Programa de Pós-Graduação em Ciências da Reabilitação, Universidade Federal de Santa Catarina (UFSC), Araranguá, SC, Brazil. \\ ${ }^{2}$ Programa de Pós-Graduação em Saúde Coletiva, Universidade Federal do Maranhão (UFMA), São Luís, MA, Brazil. ${ }^{3}$ Programa de Pós- \\ Graduação em Saúde Coletiva, UFSC, Florianópolis, SC, Brazil. ${ }^{4}$ Departamento de Clinica Médica, UFSC, Florianópolis, SC, Brazil. ${ }^{5}$ Senior \\ Research, Department of Epidemiology and Public Health, University College London, Bloomsbury, London, England.
}

\begin{abstract}
Objective: To evaluate the relationship between presence of depressive symptoms and risk of death in older adults residing in a municipality in Southern Brazil.

Methods: Between 2009 and 2014, 1,391 people participated in the EpiFloripa Aging Cohort Study, a population-based longitudinal study. Depressive symptoms were assessed through the Geriatric Depression Scale. The initial time was considered the age at the first interview, and the end time, the age at the last contact or death. Cox regression models were used to estimate the mortality risk associated with depressive symptoms, adjusted by sex, education, income, paid work, smoking status, alcohol consumption, morbidities, medication use, physical activity, disability, cognitive impairment, and body mass index.

Results: The prevalence of depressive symptoms was $23.5 \%(95 \% \mathrm{Cl} 20.4-26.9)$. On crude analysis, the risk of mortality was $1.86(95 \% \mathrm{Cl} 1.35-2.55)$ for individuals with depressive symptoms; in adjusted models, the risk of mortality was $1.67(95 \% \mathrm{Cl} 1.15-2.40)$.

Conclusion: Depressive symptoms are an independent risk factor for mortality in older Brazilian adults. Our findings highlight the importance of screening this population for depression and the practice of preventive actions.
\end{abstract}

Keywords: Depression; epidemiology; mortality; elderly

\section{Introduction}

Aging has been associated with potential declines in mental health and quality of life. As expected, such declines have a greater impact in old age compared to any other age group. Increases in life expectancy are an achievement; however, they can also bring about adverse implications in almost all aspects of life, e.g., multimorbidity, unemployment, bereavement, cognitive impairment, poverty, and social isolation. All these factors threaten the mental health and quality of life of older adults. The most common mental health conditions in older adults are depression and anxiety. ${ }^{1,2}$ The World Health Organization (WHO) predicted that, by 2020, depression would become the third leading cause of disability worldwide. ${ }^{3}$ The current global prevalence of depression is $4.4 \%^{3}$; in Brazil, the prevalence of depression among older adults may vary from $6.9 \%$ up to $20.4 \%$. $^{4-6}$

Previous research has identified factors associated with both depression and depressive symptoms later in

Correspondence: Ione Jayce Ceola Schneider, Rodovia Governador Jorge Lacerda, 3201, Jardim das Avenidas, CEP 88906-072, Araranguá, SC, Brazil.

E-mail: ione.schneider@ufsc.br

Submitted Oct 11 2019, accepted Apr 17 2020, Epub Aug 312020. life using the Geriatric Depression Scale (GDS)., ${ }^{2,5-7}$ Depressed mood and loss of interest or pleasure in nearly all activities are the two core symptoms of major depression as defined in the DSM-5, though a strong case can be made for paying greater attention to symptoms of fatigue, sleep disturbance, anxiety, and neurocognitive and sexual dysfunction in the diagnosis and evaluation of treatment outcomes. ${ }^{8}$ Depression is a clinical diagnosis with well-defined criteria. In turn, depressive symptoms are elements that characterize the diagnosis of depression and may also be present in other diseases. Furthermore, depressive symptoms may be caused by external factors, and not necessarily by an illness. ${ }^{9}$ Symptoms of depression, anxiety, and sleep disturbance are not only harmful to quality of life, but can also exacerbate mental and physical illnesses and thus increase mortality risk. ${ }^{7,10-12}$

It is known that depression can lead to fatal comorbidities, as it is a condition that can lead to physical inactivity and decreased functional capacity. In addition, the clinical condition of patients with chronic neurodegenerative
How to cite this article: Corrêa VP, Confortin SC, d'Orsi E, de Sá-Junior AR, de Oliveira C, Schneider IJC. Depressive symptoms as an independent risk factor for mortality. Braz J Psychiatry. 2021;43:247-253. http://dx.doi.org/10.1590/1516-4446-2019-0749 
diseases deteriorates in the presence of comorbid depression. ${ }^{7,13,14}$ However, few studies have investigated the association between depression and mortality risk in older adults. Thus, the aim of this study was to investigate the relationship between presence of depressive symptoms and mortality risk in older adults residing in the municipality of Florianópolis, state of Santa Catarina, Southern Brazil.

\section{Methods}

\section{Sample}

The EpiFloripa Aging Cohort Study is a population-based study conducted with 1,391 older adults, with the baseline in 2009/2010 and the first follow-up in 2013/2014. The main aim of this cohort is to investigate the health conditions of older adults living in the urban area of Florianópolis. According to the Brazilian Institute of Geography and Statistics (IBGE), the population of Florianópolis was 408,163 as of 2009 , of which $10.9 \%$ were aged 60 years or older. By 2017, the estimated population was 485,838. Sample selection for EpiFloripa was carried out in two steps: census tracts (IBGE census units) and households. Residents aged 60 years or older in selected households were included in this cohort. Institutionalized adults were excluded at baseline because they were not considered to be living in households. Further details on the sampling process and data collection can be found elsewhere. ${ }^{15}$ The research instrument, applied as an interview, is also described in detail elsewhere ${ }^{15}$ and available online at www.epifloripa.ufsc.br.

\section{Depressive symptoms}

Depressive symptoms were evaluated using the GDS. This scale is one of the instruments most used to detect episodes of depression and its severity in older adults. The short (15-item) version of the GDS was used due to greater ease of application. ${ }^{16}$ Of the 15 items, 10 indicated the presence of symptoms when answered positively, while the rest (question numbers 1, 5, 7, 11, 13) indicated depression when answered negatively. A cutoff of six items was used to define presence of depressive symptoms. The GDS was found to have $92 \%$ sensitivity and $89 \%$ specificity when evaluated against diagnostic criteria, and its validity and reliability have been supported through both clinical practice and research. In a validation study comparing the long and short forms of the GDS for self-rating of symptoms of depression, both were successful in differentiating depressed from non-depressed adults, with a high correlation $(r=0.84$, $\mathrm{p}<0.001)^{16}$

\section{Ascertainment of mortality}

We ascertained all-cause mortality for consenting study members by linking EpiFloripa data to the Mortality Information System of the state of Santa Catarina. Mortality information was obtained up to September 2015.

\section{Covariates}

The independent variables were: sex (female, male); schooling (no formal education, 1 to 4 years, 5 to 8 years, 9 to 11 years, 12 years or more); household income per capita as a function of the national minimum wage (MW) at the time of the interview ( $\leqslant 1 \times \mathrm{MW} ; 1$ to $3 \times \mathrm{MW} ;>3$ to $5 \times \mathrm{MW}$; > 5 to $10 \times \mathrm{MW}$; > $10 \times \mathrm{MW})$, which corresponded to US\$202 in 2009 and US\$290 in 2010; paid work (yes, no); smoking status (never smoked, former smoker, current smoker); alcohol intake (never consumed, moderate consumption, abusive consumption); self-reported diagnosis of cardiovascular disease (no, yes); self-reported diagnosis of diabetes (no, yes); self-reported diagnosis of high blood pressure (no, yes); self-reported use of any medications (no, yes); dependence for activities of daily living (ADL) (dependent on up to three $A D L$, dependent on four or more $A D L)^{17}$; cognitive impairment (none or probable) ${ }^{18}$; nutritional status measured by body mass index (BMI) (underweight, normal range, overweight) ${ }^{19}$; and physical activity (sedentary, insufficiently active, physically active). ${ }^{20}$

The Mini Mental State Examination (MMSE) was used to evaluate possible cognitive impairments. Clinically, this scale is used in older adults to assess cognitive decline and monitor responses to a given treatment. ${ }^{18}$ The cutoff point differs according to educational level: 24 points for those with any formal schooling, and 20 points for illiterate respondents. ${ }^{18}$ The level of leisure physical activity was assessed through the International Physical Activity Questionnaire (IPAQ). This instrument evaluates weekly performance of physical activities related to work, transportation, housework, and leisure, lasting at least 10 continuous minutes, of moderate or vigorous intensity, during a usual week. ${ }^{20}$ Finally, an adaptation the Alcohol Use Disorders Identification Test (AUDIT), developed by the World Health Organization (WHO), was used to evaluate alcoholic beverage intake. Based on the responses to three questions, alcohol intake was classified as never consumed, moderate, or abusive. $^{21}$

\section{Statistical analysis}

We performed a complete case analysis. Absolute and relative frequencies with their respective $95 \%$ confidence intervals $(95 \% \mathrm{Cl})$ were calculated for baseline, followup, and overall. Differences were compared with the chisquare test $\left(\chi^{2}\right)$. To estimate the cumulative death risk, the age at the time of first interview was used as the initial time, and the age at the last contact or death as the final time. The age at death was identified in the Santa Catarina state Mortality Information System. The effect of depressive symptoms and a wide range of risk factors on survival time was evaluated using crude and adjusted Cox regression models, considering $p<0.05$. The proportionality of the risks over time was assessed by the Schoenfeld method after the adjusted analyses. All analyses were performed using Stata SE version 14.0 (Statistical Software 14, StataCorp LLP, College Station, TX). 


\section{Ethics statement}

The EpiFloripa Aging cohort study was approved by the Universidade Federal de Santa Catarina human research ethics committee (CAAE 16731313.0.0000.0121). All participants provided informed consent.

\section{Results}

At baseline (2009/2010), 1,702 older adults aged 60 to 104 years (median, 70 years) were interviewed (a response rate of $89.1 \%$ ). At follow-up (2013/2014), 217 participants had died, 159 had been lost to follow-up, and 129 refused to participate. Vital status was obtained for 1,543 participants. We excluded 152 from the analysis because of incomplete data. The final analytic sample thus included 1,391 older adults (Figure 1).

Losses to follow-up were significantly higher among those with fewer years of schooling, no cardiovascular diseases, no diabetes, no medication use, and dependence for up to three ADL. Analysis of losses among complete cases showed a significantly higher rate for those with fewer years of schooling, low household income per capita, no current medications, and with cognitive impairment (data not shown).

Characteristics of the included participants according to their depressive symptoms are shown in Table 1. The majority of the participants were women, with 1 to 4 years of schooling, a household income of up to three times the MW, unemployed, who never smoked and never consumed alcohol. Regarding their health conditions,

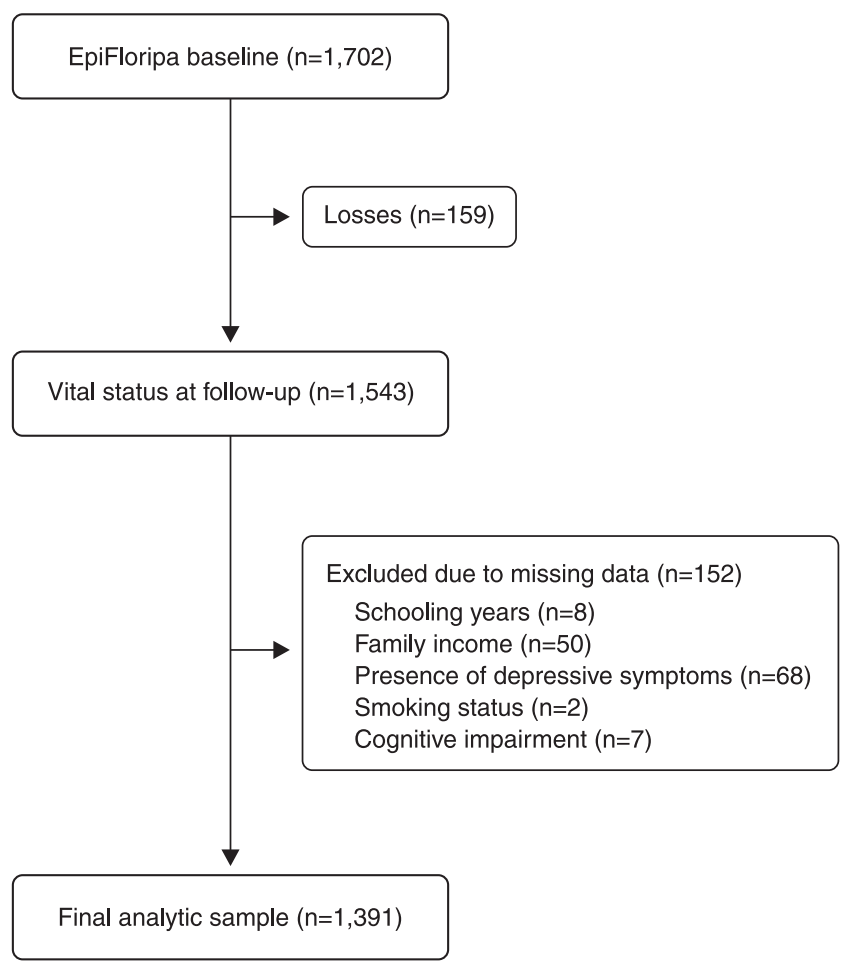

Figure 1 Flow diagram of participant selection from baseline (2009/2010), EpiFloripa, Florianópolis, 2009/2010 and 2013/ 2014. most were not diagnosed with cardiovascular disease or diabetes; however, $59 \%$ had a diagnosis of high blood pressure and $90.4 \%$ were taking medication. They were not dependent for ADL and had no cognitive impairment. Most were overweight and sedentary.

The overall prevalence of depressive symptoms was $23.5 \%(95 \% \mathrm{Cl} 20.4-26.9)$. This rate was higher in women, illiterate subjects, unemployed subjects, those with a household income less than five times the MW, those who never consumed alcohol, those with comorbidities, those taking medication, those with four or more ADL limitations, and those who were sedentary. On unadjusted analysis, the risk of death was significantly increased for those with depressive symptoms, in addition to former and current smokers, those with diabetes, those with four or more ADL difficulties, and those taking medications. The risk was lower for women and physically active participants (Table 2).

In the fully adjusted analysis, the risk of death was $67 \%$ higher in those participants who had depressive symptoms than in those without depressive symptoms, even after adjustments by sex, years of schooling, household income, paid work, smoking, alcohol consumption, comorbidities, physical activity, dependence for ADL, and BMI (Table 2). The analysis was proportional over time (Schoenfeld test, $\mathrm{p}=0.2176$ ).

\section{Discussion}

The present study showed that the presence of depressive symptoms is an independent risk factor for mortality among older adults in Florianópolis, Southern Brazil. Similar findings have been reported in previous systematic reviews that analyzed the relationship between clinical depression or presence of depressive symptoms and mortality risk. ${ }^{22-24}$ However, the analyses from the evidence included in these systematic reviews did not control for other variables that may influence mortality risk.

In 1998, a study carried out with 1,225 Finnish older adults evaluated the relationship between death rate and major clinical depression. At the end of follow-up, $60 \%$ of men with depression at baseline died compared to $32 \%$ of those without depression. The result was similar for women: $47 \%$ with and $23 \%$ without depression died. ${ }^{24}$

A prospective cohort study in Florida evaluated 879 older adults and analyzed their mortality rate at 15-year follow-up, adjusting for demographics, behavior, general health conditions, and chronic diseases. The total mortality rate was $70 \%$. The prevalence of depression at baseline was not predictive of mortality after 15 years of follow-up. However, for those participants whose depression scores had increased over the years, the mortality risk also increased by $57 \%{ }^{25}$ Another cohort study conducted in Greece with 676 elderly individuals estimated that after follow-up, $25 \%$ of the participants died. After adjustments for covariates, depressive symptoms were responsible for a $51 \%$ increase in the risk of all-cause mortality. ${ }^{26}$

In contrast, a longitudinal study in Australia with 896 community-dwelling older adults (aged 70 to 97 years) showed no significant relationship between depression and mortality. ${ }^{27}$ 
Table 1 Descriptive analyses and frequency of depressive symptoms at baseline, EpiFloripa, Florianópolis, 2009/2010

\begin{tabular}{|c|c|c|c|c|c|}
\hline \multirow[b]{2}{*}{ Variable } & \multirow[b]{2}{*}{$\mathrm{n}$} & \multirow[b]{2}{*}{$\%(95 \% \mathrm{Cl})$} & \multicolumn{3}{|c|}{ Presence of depressive symptoms ( $\geqslant 6$ symptoms) } \\
\hline & & & $\mathrm{n}$ & $\%(95 \% \mathrm{Cl})$ & $\mathrm{p}$-value \\
\hline Gender & & & & & 0.015 \\
\hline Male & 507 & $38.4(35.3-41.6)$ & 101 & $19.8(16.3-23.8)$ & \\
\hline Female & 884 & $61.6(58.4-64.7)$ & 236 & $25.8(22.1-29.8)$ & \\
\hline Educational attainment & & & & & $<0.001$ \\
\hline Illiterate & 119 & $6.9(5.3-9.1)$ & 55 & $45.2(32.9-58.1)$ & \\
\hline 1 to 4 years & 509 & 34.1 (28.7-39.9) & 156 & $31.9(26.9-37.5)$ & \\
\hline 5 to 8 years & 240 & $16.6(14.3-19.2)$ & 53 & $19.7(14.7-25.9)$ & \\
\hline 9 to 11 years & 207 & $17.3(14.8-20.1)$ & 34 & $17.4(10.6-27.2)$ & \\
\hline 12 years or more & 316 & $25.1(20.1-30.7)$ & 39 & $12.7(9.1-17.6)$ & \\
\hline Family income per capita, $\times \mathrm{MW}$ & & & & & $<0.001$ \\
\hline$\leqslant 1 \times \mathrm{MW}$ & 159 & $9.8(7.6-12.5)$ & 44 & $24.2(17.5-32.5)$ & \\
\hline$>1$ to $3 \times M W$ & 353 & $24.9(20.8-29.5)$ & 106 & $30.1(24.6-36.1)$ & \\
\hline$>3$ to $5 \times \mathrm{MW}$ & 268 & $18.8(16.5-21.5)$ & 76 & $31.0(23.8-39.4)$ & \\
\hline$>5$ to $10 \times \mathrm{MW}$ & 323 & $24.1(21.3-27.2)$ & 67 & $17.4(13.2-22.6)$ & \\
\hline$>10 \times \mathrm{MW}$ & 288 & $22.4(18.2-27.1)$ & 44 & $16.1(11.7-21.7)$ & \\
\hline Paid work & & & & & 0.002 \\
\hline No & 1,198 & $86.3(84.1-88.3)$ & 303 & $24.6(21.4-28.0)$ & \\
\hline Yes & 193 & $13.7(11.7-15.9)$ & 34 & $16.7(11.0-24.6)$ & \\
\hline Smoking status & & & & & 0.823 \\
\hline Never & 838 & $59.0(55.4-62.4)$ & 213 & $23.1(19.2-27.5)$ & \\
\hline Former & 435 & 32.7 (29.3-36.2) & 99 & $23.7(18.2-30.3)$ & \\
\hline Current & 118 & $8.4(6.8-10.2)$ & 25 & $25.2(14.4-40.2)$ & \\
\hline Alcohol consumption & & & & & $<0.001$ \\
\hline Never & 907 & $63.9(59.8-67.8)$ & 257 & $27.1(23.8-30.7)$ & \\
\hline Moderate & 250 & $18.3(15.0-22.1)$ & 41 & $17.6(11.0-26.9)$ & \\
\hline Abusive & 234 & $17.8(14.7-21.4)$ & 39 & $16.7(11.9-23.0)$ & \\
\hline Cardiovascular disease & & & & & $<0.001$ \\
\hline No & 981 & $70.5(67.6-73.3)$ & 191 & $18.5(15.3-22.2)$ & \\
\hline Yes & 410 & $29.5(26.7-32.4)$ & 146 & $35.4(28.8-42.6)$ & \\
\hline Diabetes & & & & & $<0.001$ \\
\hline No & 1,072 & $77.7(73.6-81.3)$ & 220 & $20.1(17.3-23.3)$ & \\
\hline Yes & 319 & $22.3(18.7-26.4)$ & 117 & $35.4(28.5-42.9)$ & \\
\hline Hypertension & & & & & $<0.001$ \\
\hline No & 555 & $41.0(37.9-44.2)$ & 102 & $17.3(13.8-21.6)$ & \\
\hline Yes & 836 & $59.0(55.8-62.1)$ & 235 & $27.8(23.7-32.3)$ & \\
\hline Current medication & & & & & 0.003 \\
\hline None & 126 & $9.6(7.7-11.9)$ & 14 & $13.9(7.6-24.0)$ & \\
\hline Any & 1,265 & $90.4(88.1-92.3)$ & 323 & $24.5(21.3-28.1)$ & \\
\hline ADL difficulties & & & & & $<0.001$ \\
\hline$\leqslant 3 \mathrm{ADL}$ & 965 & $68.8(65.2-72.2)$ & 137 & $12.7(10.6-15.2)$ & \\
\hline$\geqslant 4 \mathrm{ADL}$ & 426 & $31.2(27.8-34.8)$ & 200 & $47.3(41.0-53.7)$ & \\
\hline Cognitive impairment & & & & & $<0.001$ \\
\hline No & 1,061 & $79.0(73.8-83.4)$ & 199 & $18.1(15.3-21.3)$ & \\
\hline Yes & 330 & $21.0(16.6-26.2)$ & 138 & $43.7(37.6-50.0)$ & \\
\hline BMI & & & & & 0.581 \\
\hline Normal range & 538 & $39.1(36.5-41.7)$ & 119 & $21.1(16.7-26.2)$ & \\
\hline Underweight & 122 & $8.3(6.9-9.9)$ & 32 & $26.1(17.6-36.7)$ & \\
\hline Overweight & 731 & $52.6(49.8-55.4)$ & 186 & $24.9(20.0-30.6)$ & \\
\hline Physical activity & & & & & $<0.001$ \\
\hline Sedentary & 748 & $51.6(46.6-56.6)$ & 235 & $31.8(27.1-36.8)$ & \\
\hline Insufficiently active & 229 & $16.2(14.1-18.5)$ & 44 & $17.8(12.6-24.6)$ & \\
\hline Physically active & 414 & $32.2(27.6-37.2)$ & 58 & $13.1(10.1-16.8)$ & \\
\hline
\end{tabular}

$95 \% \mathrm{Cl}=95 \%$ confidence interval; $\mathrm{ADL}=$ activities of daily living; $\mathrm{BMI}=$ body mass index; $\mathrm{MW}=$ minimum wage. 
Table 2 Crude and adjusted hazard ratios for the relationship between depressive symptoms and mortality risk, EpiFloripa, Florianópolis

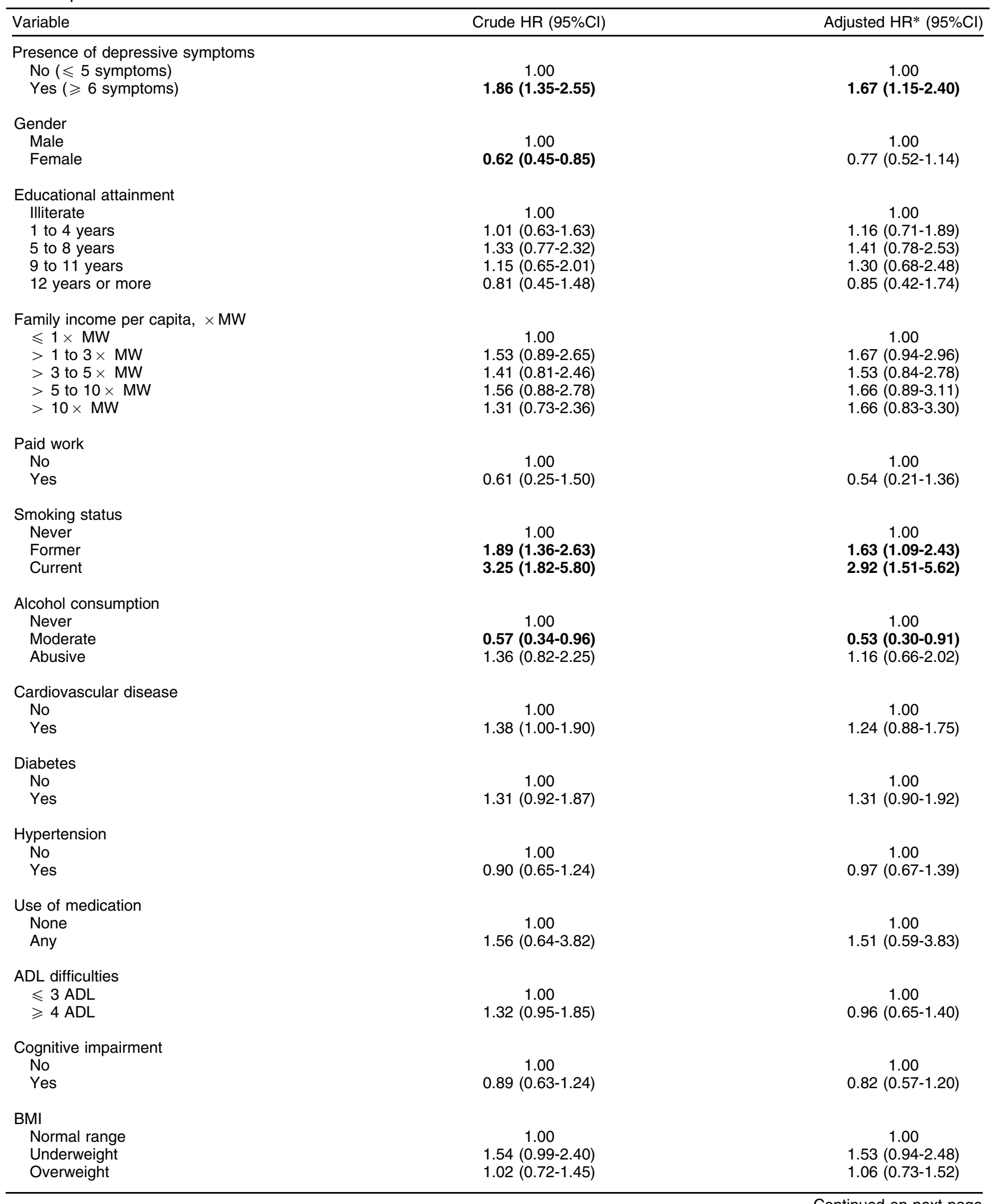


Table 2 (continued)

\begin{tabular}{lcr}
\hline Variable & Crude HR $(95 \% \mathrm{Cl})$ & Adjusted HR* $(95 \% \mathrm{Cl})$ \\
\hline Physical activity & & 1.00 \\
Sedentary & 1.00 & $0.68(0.41-1.13)$ \\
Insufficiently active & $0.69(0.42-1.13)$ & $0.66(0.42-1.04)$ \\
Physically active & $\mathbf{0 . 6 4}(\mathbf{0 . 4 1 - 0 . 9 8 )}$ & \\
\hline
\end{tabular}

$95 \% \mathrm{Cl}=95 \%$ confidence interval; $\mathrm{ADL}=$ activities of daily living; $\mathrm{BMI}=$ body mass index; $\mathrm{HR}=\mathrm{Hazard}$ ratio; $\mathrm{MW}=$ minimum wage .

* Fully adjusted model.

Bold type denotes significant differences $(95 \% \mathrm{Cl}$ does not include the null value of 1$)$.

Evidence shows that women have a higher prevalence of depression. ${ }^{11,28,29}$ However, our results showed no mortality risk association with sex in the fully adjusted models. Results from the Survey of Health and Living Status of the Elderly in Taiwan (people aged 65 or older) showed that depressive symptoms predicted all-cause mortality. However, when the authors examined gender differences, the association only remained significant in men. ${ }^{30} \mathrm{~A}$ potential explanation for the observed sex differences could be the fact that women are more likely to use health services and thus obtain early diagnosis and adequate treatment. $^{29}$ In addition, the literature on sex differences highlights others factors that could explained the rationale for women being more vulnerable to depression, i.e., social roles and cultural norms, adverse life events, coping style, poor social support, and genetic and biological factors. ${ }^{31}$

Another important aspect to consider regarding the relationship between depressive symptoms and mortality risk relates to the duration of such symptoms. Results from the English Longitudinal Study of Ageing (ELSA) demonstrated a clear dose-response association between the duration of depressive symptoms and mortality risk; the risk also increased as the number of waves with depressive symptoms increased. This association was partially explained by functional impairments and physical illnesses, physical inactivity, and poor cognitive function. ${ }^{32}$ In the same ELSA population, the severity of depressive symptoms was also associated with all-cause mortality. People with low to moderate symptoms scores had increased mortality risk. This association was attenuated by levels of physical inactivity, cognitive function, functional impairments, and physical illnesses. However, people with low scores do not usually attract the attention of the health services. ${ }^{33}$

Other mortality risk factors considered in this study were smoking and excessive alcohol consumption, since they are considered risk factors for chronic noncommunicable diseases and are predictors of mortality later in life. ${ }^{34}$ Smoking was an independent factor for increased mortality risk in both current and former smokers. Recent evidence shows that smoking cessation should be encouraged, and is not associated with exacerbated symptoms of depression. ${ }^{35}$ We found that moderate alcohol consumption reduced the mortality risk independently of depressive symptoms. A general health improvement is observed when an individual who consumes alcohol excessively is treated and quits drinking. ${ }^{36}$ However, moderate consumption was not associated with a mortality risk increase in our study. Furthermore, good self-reported physical and mental health are consistent over time in older adults who drink more often ${ }^{37}$ and there is a nonsignificant trend toward a lower risk of depression and psychological distress associated with heavy drinking. ${ }^{38}$

Sedentary behavior is one of the most common unhealthy lifestyle habits among older adults. Physical activity directly contributes to the prevention of functional decline $^{39}$ and chronic diseases, ${ }^{34}$ and it has been associated with reduction of depression in Brazilian men. ${ }^{40}$ In the present study, physically active older adults had a lower risk of death compared to those who were sedentary. However, this finding did not remain significant in the fully adjusted analysis.

Our study has several strengths and several potential limitations that need to be acknowledged. The first strength was to use age as the follow-up time and not the time the person remained in the cohort in our survival analysis. This procedure automatically adjusted the analyses for the greatest risk of death from the aging process. ${ }^{41}$ Another positive point was the use of an easily administered, validated, and standardized tool to detect the presence of depressive symptoms in older adults, i.e., the GDS scale. EpiFloripa is the first population-based aging cohort in the state of Santa Catarina and presented an excellent response rate in both waves. Our analyses were adjusted for a wide range of important covariates associated with both depression and increased mortality risk.

Non-participation in the surveys over the follow-up period could be a source of bias. However, this type of bias is unavoidable in longitudinal studies of aging that only include community-dwelling older adults. Another source of bias relates to the generalizability of our findings. The selective loss of follow-up in some variables may have led to inaccurate results. However, the majority of the losses were observed among the healthier participants, i.e., there was an underestimation of our findings.

In conclusion, depressive symptoms were an independent risk factor for mortality in this cohort of older adults in Florianópolis, Southern Brazil. Depression is already a priority in the Brazilian National Health Policy for the Elderly. However, our main finding highlights the need for additional investments in health promotion and awareness campaigns around this topic in older age. This would facilitate follow-up, proper diagnosis, and, if necessary, treatment of older adults with depressive symptoms. Further studies are needed to evaluate the association between depressive symptoms and mortality risk at the national level and, potentially, improve survival rates.

\section{Acknowledgements}

This study received financial support from Conselho Nacional de Desenvolvimento Científico e Tecnológico 
(CNPq; grant 569834/2008 2). VPC received a master's scholarship grant from Coordenação de Aperfeiçoamento de Pessoal de Nível Superior (CAPES). SCC received a postdoctoral scholarship grant from CAPES and Departamento de Ciência e Tecnologia (DECIT).

The authors are grateful to the Brazilian Institute of Geography and Statistics (IBGE) and Florianópolis health authority staff for their useful help with the practical aspects of the study.

\section{Disclosure}

The authors report no conflicts of interest.

\section{References}

$1 \mathrm{Kim} \mathrm{C}, \mathrm{Ko} \mathrm{H}$. The impact of self-compassion on mental health, sleep, quality of life and life satisfaction among older adults. Geriatr Nurs. 2018;39:623-8.

2 Alvarenga MRM, Oliveira MAC, Faccenda O. Depressive symptoms in the elderly: analysis of the items of the geriatric depression scale. Acta Paul Enferm. 2012;25:497-503.

3 World Health Organization (WHO). Depression and other common mental disorders. Geneva: WHO; 2017.

4 Stopa SR, Malta DC, de Oliveira MM, Lopes CS, Menezes PR, Kinoshita RT. Prevalência do autorrelato de depressão no Brasil: resultados da Pesquisa Nacional de Saúde, 2013. Rev Bras Epidemiol. 2015;18 Suppl 2:170-80.

5 Gullich I, Duro SMS, Cesar JA. Depression among the elderly: a population-based study in Southern Brazil. Rev Bras Epidemiol. 2016;19:691-701.

6 Borges LJ, Benedetti TRB, Xavier AJ, D'Orsi E. Associated factors of depressive symptoms in the elderly: EpiFloripa study. Rev Saude Publica. 2013;47:701-10.

7 Semedo DC, Ventura J, de Paula SF, da Silva MRS, Pelzer MT. Fatores associados a depressão e os cuidados de enfermagem no idoso. Rev Enferm. 2016;12:101-13.

8 Kennedy $\mathrm{SH}$. Core symptoms of major depressive disorder: relevance to diagnosis and treatment. Dialogues Clin Neurosci. 2008;10: 271-7.

9 Spanemberg L. Depression and depressive symptoms: conceptual confusion. J Bras Psiquiatr. 2010;59:258.

10 Gazalle FK, de Lima MS, Tavares BF, Hallal PC. [Depressive symptoms and associated factors in an elderly population in southern Brazil]. Rev Saude Publica. 2004;38:365-71.

11 Pinho MX, Custódio O, Makdisse M. Incidence of depression and associated factors among elderly community-dwelling people: a literature review. Rev Bras Geriatr Gerontol. 2009;12:123-40.

12 Pramesona BA, Taneepanichskul S. The effect of religious intervention on depressive symptoms and quality of life among Indonesian elderly in nursing homes: a quasi-experimental study. Clin Interv Aging. 2018;13:473-83.

13 Maia FO, Duarte YA, Lebrão ML, Santos JL. [Risk factors for mortality among elderly people]. Rev Saude Publica. 2006;40:1049-56.

14 Teng CT, Humes Ede C, Demetrio FN. Depressão e comorbidades clínicas. Rev Psiquiatr Clin. 2005;32:149-59.

15 Schneider IJ, Confortin SC, Bernardo CO, Bolsoni CC, Antes DL, Pereira KG, et al. EpiFloripa Aging cohort study: methods, operational aspects, and follow-up strategies. Rev Saude Publica. 2017;51:104.

16 Almeida OP, Almeida SA. [Reliability of the Brazilian version of the ++ abbreviated form of geriatric depression scale (GDS) short form]. Arq Neuropsiquiatr. 1999;57:421-6.

17 Rosa TE, Benício MH, Latorre MR, Ramos LR. [Determinant factors of functional status among the elderly]. Rev Saude Publica. 2003;37: 40-8.

18 Almeida OP. [Mini mental state examination and the diagnosis of dementia in Brazil]. Arq Neuropsiquiatr. 1998;56:605-12.

19 World Health Organization (WHO). Physical status: the use and interpretation of anthropometry. Technical Report Series $N^{\circ} 854$. Geneva: WHO; 1995.
20 Mazo GZ, Benedetti TB. Adaptation of the international physical activity questionnarie for the elderly. Rev Bras Cineantropometria e Desempenho Hum. 2010;12:480-4.

21 Meneses-Gaya C, Zuardi AW, Loureiro SR, Hallak JE, Trzesniak C, de Azevedo Marques JM, et al. Is the full version of the AUDIT really necessary? Study of the validity and internal construct of its abbreviated versions. Alcohol Clin Exp Res. 2010;34:1417-24.

22 Schulz R, Drayer RA, Rollman BL. Depression as a risk factor for non-suicide mortality in the elderly. Biol Psychiatry. 2002;52: 205-25.

23 Saz P, Dewey ME. Depression, depressive symptoms and mortality in persons aged 65 and over living in the community: a systematic review of the literature. Int J Geriatr Psychiatry. 2001;16:622-30.

24 Pulska T, Pahkala K, Laippalla P, Kivelä SL. Major depression as a predictor of premature deaths in elderly people in Finland: a community study. Acta Psychiatr Scand. 1998;97:408-11.

25 Zhang JP, Kahana B, Kahana E, Hu B, Pozuelo L. Joint modeling of longitudinal changes in depressive symptoms and mortality in a sample of community-dwelling elderly people. Psychosom Med. 2009;71:704-14.

26 Georgakis MK, Papadopoulos FC, Protogerou AD, Pagonari I, Sarigianni F, Biniaris-Georgallis SI, et al. Comorbidity of cognitive impairment and late-life depression increase mortality: results from a cohort of community-dwelling elderly individuals in rural greece. J Geriatr Psychiatry Neurol. 2016;29:195-204.

27 Batterham PJ, Christensen H, MacKinnon AJ. Mental health symptoms associated with morbidity, not mortality, in an elderly community sample. Soc Psychiatry Psychiatr Epidemiol. 2012;47:79-85.

28 Hellwig N, Munhoz TN, Tomasi E. [Depressive symptoms among the elderly: a cross-sectional population-based study]. Cien Saude Colet. 2016;21:3575-84.

29 Rombaldi AJ, da Silva MC, Gazalle FK, Azevedo MR, Hallal PC. [Prevalence of depressive symptoms and associated factors among southern Brazilian adults: cross-sectional population-based study]. Rev Bras Epidemiol. 2010;13:620-9.

30 Teng PR, Yeh CJ, Lee MC, Lin HS, Lai TJ. Depressive symptoms as an independent risk factor for mortality in elderly persons: results of a national longitudinal study. Aging Ment Health. 2013;17:470-8.

31 Piccinelli M, Wilkinson G. Gender differences in depression. Critical review. Br J Psychiatry. 2000;177:486-92.

32 White J, Zaninotto P, Walters K, Kivimäki M, Demakakos P, Biddulph $\mathrm{J}$, et al. Duration of depressive symptoms and mortality risk: the English longitudinal study of ageing (ELSA). Br J Psychiatry. 2016;208: 337-42.

33 White J, Zaninotto P, Walters K, Kivimäki M, Demakakos P, Shankar A, et al. Severity of depressive symptoms as a predictor of mortality: the English longitudinal study of ageing. Psychol Med. 2015;45: 2771-9.

34 Benziger CP, Roth GA, Moran AE. The global burden of disease study and the preventable burden of NCD. Glob Heart. 2016;11:393-7.

35 Morozova M, Rabin RA, George TP. Co-morbid tobacco use disorder and depression: a re-evaluation of smoking cessation therapy in depressed smokers. Am J Addict. 2015;24:687-94.

36 Charlet K, Heinz A. Harm reduction -a systematic review on effects of alcohol reduction on physical and mental symptoms. Addict Biol. 2017;22:1119-59.

37 Holdsworth C, Mendonça M, Pikhart H, Frisher M, de Oliveira C, Shelton N. Is regular drinking in later life an indicator of good health? Evidence from the English longitudinal study of ageing. J Epidemiol Community Health. 2016;70:764-70.

38 García-Esquinas E, Ortolá R, Galán I, Soler-Vila H, Laclaustra M, Rodríguez-Artalejo F. Moderate alcohol drinking is not associated with risk of depression in older adults. Sci Rep. 2018;8:11512.

39 Hrubeniuk TJ, Sénéchal M, Mayo A, Bouchard DR. Association between physical function and various patterns of physical activity in older adults: a cross-sectional analysis. Aging Clin Exp Res. 2020;32: 1017-24.

40 de Oliveira GD, Oancea SC, Nucci LB, Vogeltanz-Holm N. The association between physical activity and depression among individuals residing in Brazil. Soc Psychiatry Psychiatr Epidemiol. 2018;53:373-83.

41 Lamarca R, Alonso J, Gómez G, Muñoz A. Left-truncated data with age as time scale: an alternative for survival analysis in the elderly population. J Gerontol A Biol Sci Med Sci. 1998;53:M337-43. 


\section{Corrigendum}

http://dx.doi.org/10.1590/1516-4446-2021-0029

We hereby correct and complement the Tables 1 and 2 present in the article titled "Depressive symptoms as an independent risk factor for mortality" (http://dx.doi.org/10.1590/1516-4446-2019-0749), by Corrêa et al., published in the Brazilian Journal of Psychiatry in August 2020 in ahead of print mode and now as part of the present issue (pages 247-253).

In Table 1, reference to the second time period ("and 2013/2014") was removed from the title. In addition, a new "n" subcolumn was added under "Presence of depressive symptoms ( $\geqslant 6$ symptoms)," at the editors' request, indicating the number of patients to which the percentages and $90 \%$ confidence intervals presented next refer. Below we reproduce the revised, correct version of Table 1:

Table 1 Descriptive analyses and frequency of depressive symptoms at baseline, EpiFloripa, Florianópolis, 2009/2010

\begin{tabular}{|c|c|c|c|c|c|}
\hline \multirow[b]{2}{*}{ Variable } & \multirow[b]{2}{*}{$\mathrm{n}$} & \multirow[b]{2}{*}{$\%(95 \% \mathrm{Cl})$} & \multicolumn{3}{|c|}{ Presence of depressive symptoms ( $\geqslant 6$ symptoms) } \\
\hline & & & $\mathrm{n}$ & $\%(95 \% \mathrm{Cl})$ & p-value \\
\hline Gender & & & & & 0.015 \\
\hline Male & 507 & $38.4(35.3-41.6)$ & 101 & $19.8(16.3-23.8)$ & \\
\hline Female & 884 & $61.6(58.4-64.7)$ & 236 & $25.8(22.1-29.8)$ & \\
\hline Educational attainment & & & & & $<0.001$ \\
\hline Illiterate & 119 & $6.9(5.3-9.1)$ & 55 & $45.2(32.9-58.1)$ & \\
\hline 1 to 4 years & 509 & $34.1(28.7-39.9)$ & 156 & $31.9(26.9-37.5)$ & \\
\hline 5 to 8 years & 240 & $16.6(14.3-19.2)$ & 53 & $19.7(14.7-25.9)$ & \\
\hline 9 to 11 years & 207 & $17.3(14.8-20.1)$ & 34 & $17.4(10.6-27.2)$ & \\
\hline 12 years or more & 316 & $25.1(20.1-30.7)$ & 39 & $12.7(9.1-17.6)$ & \\
\hline Family income per capita, $\times \mathrm{MW}$ & & & & & $<0.001$ \\
\hline$\leqslant 1 \times M W$ & 159 & $9.8(7.6-12.5)$ & 44 & $24.2(17.5-32.5)$ & \\
\hline$>1$ to $3 \times \mathrm{MW}$ & 353 & $24.9(20.8-29.5)$ & 106 & $30.1(24.6-36.1)$ & \\
\hline$>3$ to $5 \times \mathrm{MW}$ & 268 & $18.8(16.5-21.5)$ & 76 & $31.0(23.8-39.4)$ & \\
\hline$>5$ to $10 \times \mathrm{MW}$ & 323 & $24.1(21.3-27.2)$ & 67 & $17.4(13.2-22.6)$ & \\
\hline$>10 \times \mathrm{MW}$ & 288 & $22.4(18.2-27.1)$ & 44 & $16.1(11.7-21.7)$ & \\
\hline Paid work & & & & & 0.002 \\
\hline No & 1,198 & $86.3(84.1-88.3)$ & 303 & $24.6(21.4-28.0)$ & \\
\hline Yes & 193 & $13.7(11.7-15.9)$ & 34 & $16.7(11.0-24.6)$ & \\
\hline Smoking status & & & & & 0.823 \\
\hline Never & 838 & $59.0(55.4-62.4)$ & 213 & $23.1(19.2-27.5)$ & \\
\hline Former & 435 & $32.7(29.3-36.2)$ & 99 & $23.7(18.2-30.3)$ & \\
\hline Current & 118 & $8.4(6.8-10.2)$ & 25 & $25.2(14.4-40.2)$ & \\
\hline Alcohol consumption & & & & & $<0.001$ \\
\hline Never & 907 & $63.9(59.8-67.8)$ & 257 & $27.1(23.8-30.7)$ & \\
\hline Moderate & 250 & $18.3(15.0-22.1)$ & 41 & $17.6(11.0-26.9)$ & \\
\hline Abusive & 234 & $17.8(14.7-21.4)$ & 39 & $16.7(11.9-23.0)$ & \\
\hline Cardiovascular disease & & & & & $<0.001$ \\
\hline No & 981 & $70.5(67.6-73.3)$ & 191 & $18.5(15.3-22.2)$ & \\
\hline Yes & 410 & $29.5(26.7-32.4)$ & 146 & $35.4(28.8-42.6)$ & \\
\hline Diabetes & & & & & $<0.001$ \\
\hline No & 1,072 & 77.7 (73.6-81.3) & 220 & $20.1(17.3-23.3)$ & \\
\hline Yes & 319 & $22.3(18.7-26.4)$ & 117 & $35.4(28.5-42.9)$ & \\
\hline
\end{tabular}


Table 1 (continued)

\begin{tabular}{|c|c|c|c|c|c|}
\hline \multirow[b]{2}{*}{ Variable } & \multirow[b]{2}{*}{$\mathrm{n}$} & \multirow[b]{2}{*}{$\%(95 \% \mathrm{Cl})$} & \multicolumn{3}{|c|}{ Presence of depressive symptoms ( $\geqslant 6$ symptoms) } \\
\hline & & & $\mathrm{n}$ & $\%(95 \% \mathrm{Cl})$ & $p$-value \\
\hline Hypertension & & & & & $<0.001$ \\
\hline No & 555 & $41.0(37.9-44.2)$ & 102 & $17.3(13.8-21.6)$ & \\
\hline Yes & 836 & $59.0(55.8-62.1)$ & 235 & $27.8(23.7-32.3)$ & \\
\hline Current medication & & & & & 0.003 \\
\hline None & 126 & $9.6(7.7-11.9)$ & 14 & $13.9(7.6-24.0)$ & \\
\hline Any & 1,265 & $90.4(88.1-92.3)$ & 323 & $24.5(21.3-28.1)$ & \\
\hline ADL difficulties & & & & & $<0.001$ \\
\hline$\leqslant 3 \mathrm{ADL}$ & 965 & $68.8(65.2-72.2)$ & 137 & $12.7(10.6-15.2)$ & \\
\hline$\geqslant 4 \mathrm{ADL}$ & 426 & $31.2(27.8-34.8)$ & 200 & $47.3(41.0-53.7)$ & \\
\hline Cognitive impairment & & & & & $<0.001$ \\
\hline No & 1,061 & $79.0(73.8-83.4)$ & 199 & $18.1(15.3-21.3)$ & \\
\hline Yes & 330 & $21.0(16.6-26.2)$ & 138 & $43.7(37.6-50.0)$ & \\
\hline BMI & & & & & 0.581 \\
\hline Normal range & 538 & $39.1(36.5-41.7)$ & 119 & $21.1(16.7-26.2)$ & \\
\hline Underweight & 122 & $8.3(6.9-9.9)$ & 32 & $26.1(17.6-36.7)$ & \\
\hline Overweight & 731 & $52.6(49.8-55.4)$ & 186 & $24.9(20.0-30.6)$ & \\
\hline Physical activity & & & & & $<0.001$ \\
\hline Sedentary & 748 & $51.6(46.6-56.6)$ & 235 & $31.8(27.1-36.8)$ & \\
\hline Insufficiently active & 229 & $16.2(14.1-18.5)$ & 44 & $17.8(12.6-24.6)$ & \\
\hline Physically active & 414 & $32.2(27.6-37.2)$ & 58 & $13.1(10.1-16.8)$ & \\
\hline
\end{tabular}

$95 \% \mathrm{Cl}=95 \%$ confidence interval; $\mathrm{ADL}=$ activities of daily living; $\mathrm{BMI}=$ body mass index; $\mathrm{MW}=$ minimum wage.

In Table 2, considering that only one measure is presented, reference to the two study time periods was removed from the title ("2009/2010 and 2013/2014").

Table 2 Crude and adjusted hazard ratios for the relationship between depressive symptoms and mortality risk, EpiFloripa, Florianópolis 